\title{
Fungi resistant grape variety diffusion: a multi-scale, multi-factor approach
}

\author{
Bruno Striffler ${ }^{1}$, Julie Wohlfahrt ${ }^{1}$ and Marie Thiollet-Scholtus ${ }^{1}$ \\ ${ }^{1}$ INRA - SAD - UR-0055-ASTER, 28, rue de Herrlisheim, 68000 Colmar, France
}

\begin{abstract}
Farm dependency to inputs is an issue concerning both farms and society. Viticulture is an inputintensive sector of agriculture. Some innovations in agriculture have been designed to reduce the use of inputs, such as fungi-resistant vine varieties. As the diffusion of innovation is uneven, we will compare the characteristics of innovations in both sides of the upper Rhine River. In this way we will interview farmers and analyze the geographical context. We will also compare the farms characteristics and their contexts at various scales. We expect to get a typology of innovations, with characteristics such as the impact on various scales (e.g. cropping system, farming system) and the radicalness of the changes. We also expect to get some information about the eventual levers and incentives to innovations' diffusion, adoption or abandonment. And finally, French and German innovations will be compared to others vineyards innovations. It is possible to sharply describe several innovations reducing vineyard inputs, located on both sides of Upper Rhine River.
\end{abstract}

\section{Introduction}

Viticulture is part of the French heritage, this crop represents only $3,7 \%$ of the French agricultural acreage but represent a turnover of more than 8 billions euros [1]. Viticulture consumes $20 \%$ of the national pesticides' use, mostly fungicides (about $80 \%$ of the pesticides) [2].

Fungi resistant vine varieties seem to be a promising alternative to drastically reduce pesticides uses in vine growing. At a time when some fungi resistant vine varieties are just registered at the French and European catalogue, it seems necessary to investigate why and how these varieties could be adopted by winegrowers. The choice of vine variety is one of the key practices in viticulture as it determines, in combination with biophysical properties of the vineyard, the type and quality of the vine. Thus the introduction of fungi resistant vine varieties (as known as PiWis) must be approached considering the whole system linking biophysical environment (soil, climate), winemakers' practices and economic environment (value chains, quality marks, certification, etc.). The choice of specific varieties must meet the requirements for certifications, such as Protected Designation of Origin and Protected Geographical Indications. In this way, growing a non-certified variety can be a hazard for the winemaker's business.

The aim of our work is to understand the incentives and locks for input-sparing innovations, especially the fungi resistant vine varieties' adoption by winemakers. We consider that the adoption process is dependent on factors at different scales, the cropping system (e.g.: agronomical factors), the farming system (e.g.: organizational factors, winegrower strategy) as well as factors at the landscape scale (e.g.: winemakers strategy, wine chain structure). To conduct the study, we will use a multi-scale survey framework, applied to the specific case of fungi resistant vine varieties.

This work is included in Interreg Vitifutur project, a European research project conducted at three scales dealing with the type of information we need to target the goals. (i) viticulture, winemaking and ageing practices will be characterized at cropping system's scale; (ii) business strategy will be described at farming system's scale; (iii) agro-pedo-climatic, the legislative set of constraints and the socio-technical environment (e.g. professional social network, commercialization network and infrastructures). In that research case, we will do a comparative study of the vineyards in both sides of the Rhine River: Alsace region on the French side and Baden-Württemberg on the German side. To conduct this study, we will use a classical method of qualitative and quantitative inquiry.

\section{Material and methods}

\subsection{Data collection}

\subsubsection{Study areas}

The survey will be conducted during March-April 2018 in the Upper Rhine region, in both France (Alsace region) and Germany (Bade-Württemberg land). On the French side, the study area is located on 17 municipalities between the cities of Colmar and Mulhouse. About 30 winegrowers will be interviewed.

On the German side, the study area is located in the Bade-Württemberg land, between the cities of Lahr/Schwarzwald and Bad-Krozingen. About 20 winegrowers will be interviewed. 
In order to understand the incentives and the obstacles of the PiWis' and others innovations' diffusion at a regional scale, studied areas will be described in details.

\subsubsection{Farmers' sampling}

In France, the farmers have been chosen using the recommendation of stakeholders from the wine sector such as chamber of agriculture, Alsatian wine interprofessional council and local winegrowers' associations. They were asked for contacts of winegrowers, in the study region, using innovative technics and work organization to reduce the use of inputs. Among the list of the innovative farmers, we tried to choose a balanced number for each municipality.

In Germany, the farmers have been chosen using the recommendation of our project's partner of Landau University and the Baden-Württemberg winegrowers' association. They were asked for contacts of winegrowers, in the study region, using innovative practices and organizations to reduce the use of inputs, with a special focus on the PiWis.

Farmers have been chosen regardless of their certifications: they can be conventional or organic or biodynamic.

\subsubsection{Survey's conduct}

The whole questionnaire is conducted with the starting question: "What kind of innovation do you set up to reduce the inputs' use?". The survey will be conducted as a semi-structured interview using a questionnaire at field and farm scales. The questionnaire was divided on 12 themes such as viticulture practices, winemaking practices and business and management of the farm.

The focus on PiWis is more important in Germany than in France, as PiWis are already implanted in Germany contrary to France. Since innovation is an iterative concept, the input reduction can be both an innovation and its consequences, as shown in Figure 1. For example: reducing fertilizers can impact the cropping system's management, but the cropping system's management can also lead to a reduction of the fertilizers. We asked (i) if some change of the management has led to an input reduction and (ii) if the reduction of this input has led to a change of the management. These questions will ensure not to miss any side of an innovation. These questions will deal at any scale, i.e. cropping system, farming system. This approach can also help to understand the interactions between two innovations located in the same field or in the same farm, especially innovations including PiWis.

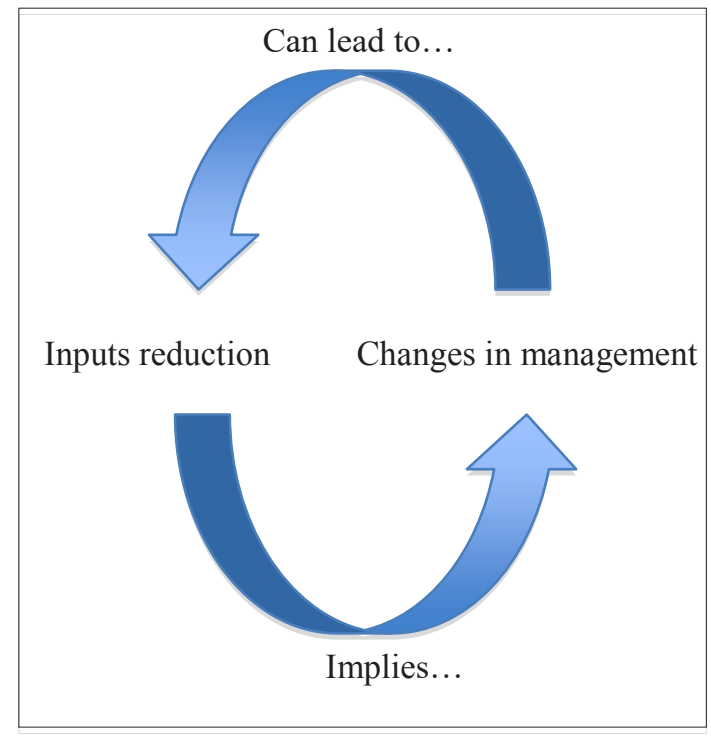

Figure 1. Iteration of the innovation process

\subsection{Interviews analysis}

\subsubsection{Characterization of highlighted innovations}

An analysis of each innovation will be conducted according to the theory of strategy analysis [3]. The characterization of highlighted innovation will be based on the questions in the surveys. The method of creating innovations typology is a constructivist agricultural method, i.e. types are defined by assumptions based on expert knowledge enriched by survey analysis [4]. For each innovation, its characteristics will be described and sorted according to their influence on the various dimension of the farm, i.e. organization or management.

The influence of an innovation is not necessarily the same in every farm. For each dimension of an innovation, its frequency of occurrence in each farm will be noted.

\subsubsection{Typology of highlighted innovations}

The output of the survey is a set of data, both quantitative and qualitative. To analyze all together, we did a Factor Analysis of Mixed Data (FAMD). The FAMD is used to see the influence and the correlation within the variables of a set. Thus this approach allows the selection of the variables explaining the most the set's diversity. This method mixes the Principal Component Analysis (PCA) and the Multiple 
Component Analysis (MCA) using factominer package with the R software [5]. PCA and MCA used respectively for qualitative and quantitative variables. The interest of this method is the possibility of using both qualitative and quantitative variables from the surveys without transforming the qualitative variables in quantitative variable. The aim of the innovation FAMD is to represent simultaneously the quantitative variables, as a PCA, and the qualitative variables, as a MCA, on the same plane. Both quantitative and qualitative variables are active variables.

\subsubsection{Geographical contextualization of highlighted innovations}

We will interview study areas experts, to understand the regional context, the socio-technical environment and the legislative set of constraint. And to understand the importance of biophysical factors, we will also cross the location of highlighted innovations with climate, topography and soil databases. Innovations location will be mapped on the GIS software QGIS according to these databases.

\section{Results and discussion}

\subsection{Characterization and typology of actual highlighted innovations}

We expect this multi-scale analysis approach to pool the highlighted innovations that have common characteristics. We are also expecting to have a sharp description of the different dimension of innovations across the studied territories. The characteristics of each innovation will be its influences on the different dimensions of the farm; its characteristics will be as well it degree of evolution from the business as usual: improvement of the efficiency, product substitution or systemic redesign (ESR) [6].

\subsection{Characterization and typology of abandoned highlighted innovations}

We expect to describe and characterize the innovations that have been abandoned by the farmers. We will describe and organize it the same way as the one that have been adopted. We will also study the reason of the abandonment and the duration of the test.

\subsection{Geographical contextualization of highlighted innovations}

Innovations characterized in Alsace and Germany study areas will be compared together and with innovations characterized in others vineyards, i.e. Bordeaux, Burgundy and Mediterranean areas [7]. We will compare the diffusion of innovations and its eventual lock-in and incentives, especially in the PiWis' case at various scales.

\section{Conclusion}

Several innovations to reduce inputs in vineyard exist on both side of the upper Rhine River. Some of innovations are not long lasting according to geographical, political or business context. Some innovations seem to be implemented in several vineyards. Are they still innovations?

This approach, applied in study areas, could then be used for various purposes. The interest for the winemaker is to determine the utility of changing the farming practices, in the studied about fungi resistant vine varieties (i.e. PIWI). Integrated in a model, the results can be used to contextualize the farmers' behavior, in order to determine the effect of policies, for example adaptations in the Protected Designation of Origin regulation.

\section{Acknowledgments}

The authors thank Interreg VITIFUTUR for funding the research project.

\section{References}

[1] Fédération des Exportateurs de Vins et Spiritueux de France, Dossier de Presse, Exportation des Vins et Spiriteux en 2017. (2018)

[2] J.-P. Butault, C.-A. Dedryver, C. Gary, L. Guichard, F. Jacquet, J.-M. Meynard, P. Nicot, M. Pitrat, R. Reau, B. Sauphanor, I. Savini, T. Volay. Rapport de recherche. Ministère de l'Ecologie, de l'Energie, du Développement Durable et de la Mer. Synthèse $d u$ rapport d'étude Ecophyto $R \& D$ : quelles voies pour réduire l'usage des pesticides? (2010)

[3] M. Crozier and E. Friedberg. Edition du seuil. L'acteur et le système. (1977)

[4] E. Landais. Le Cour. de l'Env. de l'INRA, Paris. Agriculture durable: les fondements d'un nouveau contrat social ? 33. (1998)

[5] S. Lê, J. Josse and F. Husson. J. Stat. Sof.t FactoMineR : An R Packagefor Multivariate Analysis. 25. (2008)

[6] S.B. Hill, R.J. Macrae J. Sust. Agr.. Conceptual framework for the transition from conventional to sustainable agriculture. 7(1), 81-87. (1995).

[7] A. Petit, C. Cresson, M. Chovelon, J.-M. Barbier, J.M. Meynard and M. Thiollet-Scholtus. RO 161. Recherche et évaluation de pratiques innovantes chez des viticulteurs. Offrir des pistes pour des solutions alternatives. 1-3. (2016) 